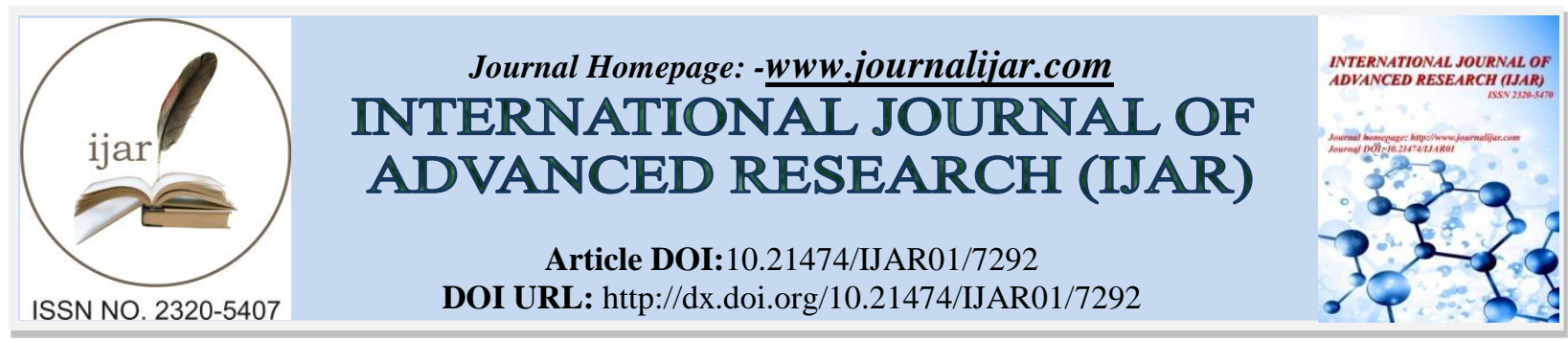

RESEARCH ARTICLE

\title{
A COMPARATIVE STUDY ON EVALUATION OF SERUM LDH IN MANAGEMENT OF HEAD AND NECK SQUAMOUS CELL CARCINOMA.
}

\author{
Arul Sundaresh Kumar Lakshmanaperumal ${ }^{1}$, Prof Dr N Dhinakaran ${ }^{2}$ and Dr Manimala ${ }^{3}$. \\ 1. Professor, Dept of ENT, Madurai Medical College. Madurai. \\ 2. Professor and HOD, Dept of ENT, Madurai Medical College. Madurai. \\ 3. Dept of ENT, Madurai Medical College. Madurai.
}

\section{Manuscript Info}

Manuscript History

Received: 15 April 2018

Final Accepted: 17 May 2018

Published: June 2018

Keywords:-

LDH, head and neck, squamous cell carcinoma.

\begin{abstract}
A neoplasm or carcinoma is an abnormal mass of tissue, the growth of which exceeds and is uncoordinated with that of normal tissues and persists in the same excessive manner after cessation of stimuli which evoked the change ${ }^{1}$.

Persistence of cancerous cells, even after the stimuli is removed is due to the heritable genetic change that is passed to tumor cell progeny. The genetic change leads to excess unregulated proliferation, which is also autonomous. All tumor cells have two compartments 1. Proliferating neoplastic cells which is the parenchyma 2 . Supportive stroma which is connective tissue and blood vessels.

Head and neck malignancy poses a significant health problem in INDIA.

In INDIA population registries estimates annual incidence of 25000 new cases of carcinoma larynx alone .

Head and neck malignancies have numerous hidden areas called" coffin corners" where tumor continues to grow.

Eventhough premalignant lesions can be clearly identified there is a significant rate of late presentation in our country.

D] Early detection and treatment is the only chance for better outcome as these tumors are aggressive compared to tumors elsewhere.

The importance of early detection will help both in cure and lessening the morbidity, thereby enabling the patients to lead a qualitatively better life.

The need for an easy and simple test that is suggestive of cancer quite early even before the patients become symptomatic and which can be done during routine visits to the health care facility at an affordable cost.
\end{abstract}

Copy Right, IJAR, 2018,. All rights reserved.

\section{Introduction:-}

Aims And Objectives:-

1. To assess the efficiency of serum lactate dehydrogenase as a biochemical marker in head and neck squamous cell carcinomas. 
2. To assess the tumor burden or load of the patient using serum lactate dehydrogenase levels

3. To assess the response to treatment mostly radiotherapy by checking fall in serum level after radiotherapy.

4. To detect early recurrence in patients treated by radiotherapy as post radiation changes effectively mask clinical examination for recurrences.

5. To compare lactate dehydrogenase levels between various histological types of head and neck cancers.

6. To assess the relationship between serum LDH levels and degree of tumor differentiation.

7. To assess the relationship between serum lactate dehydrogenase levels and morphological type of tumor.

\section{Materials And Methods:-}

A total study of 50 proven cases of head and neck squamous cell carcinoma done in department of ENT, Government Rajaji Hospital, Madurai, Tamilnadu during the period from august 2016 to august 2017. Age and sex incidence, various presentations, symptomatology and serum values of patients pre treatment and post treatment are well documentd. Treatment modalities adopted are radiotherapy and surgery. Among the 50 cases, only 3 cases underwent total laryngectomy and remaining 47 were subjected to radiotherapy.

The clinical study includes 50 patients attending department of OTORHINOLARYNGOLOGY and surgical oncology and radiotherapy, Government Rajaji hospital Madurai. The approval of the Institutional review board was obtained.

\section{Inclusion Criteria:-}

Age $=$ and $>30$ years

Histologically proven to be carcinoma of head and neck

Consent and willingness for participating in study

\section{Exclusion Criteria:-}

age $<30$ years

carcinoma of skin and thyroid

any co-morbidity

lymphoma

any other primary carcinoma or on treatment for any other malignancy

minor, prisoner,pregnancy

carcinoma in situ

patients who are considered to meet the criteria of mental incapacity

The study design is a case control study. the patients are divided into two groups.

controls

cases

\section{Controls:-}

The control group consists of 50 age matched individuals of both sexes. The control group consists of patients attending ENT OPD for problems not related to cancer. A brief clinical history and gross physical examination was done to exclude cardiac and liver disease in control group. no blood investigations other than serum lactate dehydrogenase was done in this group. Serum lactate dehydrogenase levels were taken during first visit and was not followed up with similar estimation.

\section{Study Group [Cases]:-}

The study group consisted of 50 cases of histologically confirmed head and neck squamous cell carcinoma . A thorough history and meticulous physical examination was done in all patients including indirect laryngoscopy examination and direct laryngoscopy examination.

Routine blood investigations like total count, differential count, haemoglobin \% erythrocyte sedimentation rate, blood urea, sugar and serum creatinine levels were done in all patients. Urine was tested for albumin, sugar and deposits.

Radiological examinations like $\mathrm{x}$-ray chest to rule out pulmonary secondaries, ultrasonogram to assess liver function and to rule out hepatic secondaries were done in all patients. 
Computerized tomography was done in appropriate cases to assess the extent of tumor, to note involvement of clinically silent areas like pre epiglottic, para glottis spaces etc and to pick up clinically silent neck nodes.

Magnetic resonance imaging was not done due to cost constraints.

All patients were subjected to pharyngolaryngoscopic examination under local anaesthesia and an accurate evaluation of tumor evaluation according to TNM staging, done by fibre optic Hopkins rod telescopes. Photo documentation was done in selected cases. Biopsy taken from tumor and sent for histopathological examination.

After a complete clinical and radiological evaluation patients were subjected to radiotherapy except for 3 patients who were treated by surgery . Patients requiring chemotherapy were not included in the study.

For all patients receiving radiotherapy serum levels were sampled before initiation of radiotherapy and then again on completing radiotherapy. For patients treated by surgery serum levels were taken before surgery and 2 weeks after surgery.

\section{Method Of Collection And Estimation:-}

\section{Collection:-}

As the levels of LDH can be elevated following strenuous physical activity the samples were collected after a period of rest in a relaxed supine patient, from a peripheral vein $3 \mathrm{ml}$ of blood was collected into a sterile, clean, dry container $^{34}$. Care was taken to avoid hemolysis during sampling, collection and transportation as hemolysed sample can give high values ${ }^{35}$.

\section{Estimation:-}

Estimation was done immediately once the blood sample clotted as the level of enzyme falls in a stored sample. The clotted blood was centrifuged at $3000 \mathrm{rpm}$. The clear supernatant containing serum was used for the test. The procedure was perfomed in auto analyser using LDH KIT.

\section{Observation:-}

In this study of 50 cases of head and neck squamous cell carcinoma who attended and got treated at Govt Rajaji Hospital Madurai, the following observations are made.

\begin{tabular}{|c|c|c|c|c|}
\hline & Sex & Number & Percentage & $\begin{array}{c}\text { Average age in } \\
\text { years }\end{array}$ \\
\hline Cases & MALE & 46 & $82 \%$ & 60 \\
\hline & FEMALE & 4 & $8 \%$ & 47 \\
\hline Controls & MALE & 40 & $80 \%$ & 58 \\
\hline & FEMALE & 10 & $20 \%$ & 50 \\
\hline
\end{tabular}

The study group consist of 50 cases of 46 males and 4 females, average age for males 60 years and for females 47 years.

The control group consist of 50 cases of 40 males and 10 females, average age for males 58 years and for females 50 years.

Table 2:-

\begin{tabular}{|c|c|c|c|}
\hline Control group & Number & Mean age in years & Mean serum ldh in iu/l \\
\hline Male & 40 & 58 & 236 \\
\hline Female & 10 & 50 & 198 \\
\hline
\end{tabular}

The control groups exhibited a mean serum LDH level of $236 \mathrm{IU} / \mathrm{L}$ for males and $198 \mathrm{IU} / \mathrm{L}$ for females

Table 3:-

\begin{tabular}{|c|c|c|c|c|}
\hline $\begin{array}{c}\text { Site/regional } \\
\text { distribution }\end{array}$ & Total number & Male & Female & Percentage \\
\hline Supraglottis & 20 & 19 & 1 & $40 \%$ \\
\hline Glottis & 11 & 11 & 0 & $22 \%$ \\
\hline
\end{tabular}




\begin{tabular}{|c|c|c|c|c|}
\hline Subglottis & 1 & 0 & 1 & $2 \%$ \\
\hline Hypopharynx & 8 & 7 & 1 & $16 \%$ \\
\hline Oropharynx & 10 & 9 & 1 & $20 \%$ \\
\hline
\end{tabular}

In the study group of 50 cases , 60\% had supraglottic carcinoma , 22\% had glottis carcinoma, 2\% had subglottic carcinoma, $20 \%$ had hypopharyngeal malignancy and $20 \%$ had oropharyngeal malignancy . Males outnumbered females in all categories except in subglottic category all groups had male patients.

Table 4:-

\begin{tabular}{|c|c|c|}
\hline Tumor stage & Number of patients & Mean serum ldh levels iu/l - pre treatment \\
\hline T1 & 5 & 286 \\
\hline T2 & 15 & 367.53 \\
\hline T3 & 24 & 312.37 \\
\hline T4 & 6 & 363.66 \\
\hline
\end{tabular}

In the study group t1 tumors have a mean serum LDH level of 286 IU/L , t2 tumors have 367.53 IU/L , t3 have 312.37 IU/L and t4 have 363.66 IU/L

Table 5:-

\begin{tabular}{|c|c|c|c|}
\hline Tumor differentiation & Total & Percentage & $\begin{array}{c}\text { Mean pre treatment } \\
\text { serum ldh levels iu/l }\end{array}$ \\
\hline Well differentiated & 16 & $32 \%$ & 312.875 \\
\hline Moderately differentiated & 27 & $54 \%$ & 327.07 \\
\hline Poorly differentiated & 7 & $14 \%$ & 393.14 \\
\hline P value & & & $<0.001$ Significant \\
\hline
\end{tabular}

Most of the patients have moderately differentiated carcinoma 54\% followed by well differentiated tumors $32 \%$ and poorly differentiated tumors 14\%. Their mean serum LDH levels are 312.88 \%, $327.07 \%$ and $393.14 \%$ respectively.

Table 6:-

\begin{tabular}{|c|c|c|c|c|}
\hline Treatment modality & Number of & \multicolumn{2}{|c|}{ Mean of serum ldh levels iu/l } & \multicolumn{2}{c|}{ P value } \\
\cline { 3 - 5 } & cases & Pre treatment & Post treatment & $<0.001$ \\
Sadiotherapy & 47 & 331.92 & 206.42 & Significant \\
\hline Surgery & 3 & 343 & 240.66 & Significant \\
\hline
\end{tabular}

Table 7:-

\begin{tabular}{|c|c|c|}
\hline & Number of patients & Mean serum ldh level iu/l \\
\hline Metastasis & 29 & 342.19 \\
\hline Non metastatis & 21 & 321.55 \\
\hline
\end{tabular}




\section{MEAN SERUM LDH LEVEL IU/L FOR METASTASIS VS NON METASTASIS}

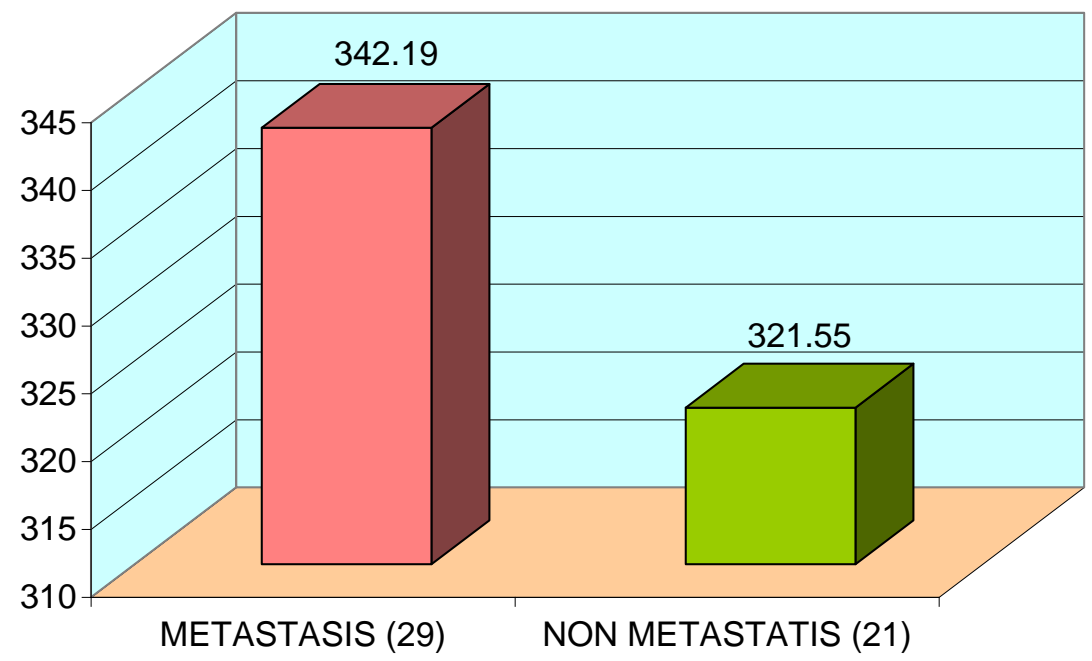

$\square$ METASTASIS (29) $\square$ NON METASTATIS (21)

\section{Discussion:-}

The study includes 50 proven cases of head and neck malignancy and 50 controls. The study has been conducted in department of ENT, MADURAI MEDICAL COLLEGE, from August 2016 to July 2017.The control group included 40 males and 10 female patients who attended ENT out patient department for all other ailment other than head and neck squamous cell carcinoma. In the control group mean age among males was 58 years and their mean serum LDH levels showed 236 IU/litre. Among female, mean age was 50 years and mean serum LDH value was $198 \mathrm{IU} / \mathrm{litre}$.

The study group includes 50 cases among which 46 patients were males and 4 were females. All females were non smokers and non alcoholic. Except for 1 female patient neuroendocrine carcinoma of larynx, others were tobacco and betel leaf chewers with or without betel leaf quid occasionally. Among 50 cases of proven head and neck squamous cell carcinoma, majority were supra glottis carcinoma, sub glottis carcinoma was rare. T3 stage was predominant followed by T2stage. Based on differentiation, moderate differentiation is of higher in number followed by well differentiated and poorly differentiated tumours

Among 50 patients, 29 had nodal metastasis. Their mean serum LDH was 342.19 IU/l. 21 patients who did not develop nodal metastasis showed their mean serum LDH value to be $321.53 \mathrm{IU} /$ litre.

The study includes 50 proven cases of head and neck squamous cell carcinoma among which 10 cases are carcinoma oropharynx, 20 cases are proven carcinoma supraglottis, 11 cases are carcinoma glottis, 1 patient belong to carcinoma sub glottis category, 8 patients are carcinoma hypopharynx

\section{Oropharynx:-}

Among ten cases of carcinoma oropharynx, only one belongs to female sex. She proved poorly differentiated squamous cell carcinoma. T staging T2 and nodal status N1. No clinical evidence of metastasis. Her USG abdomen and chest $\mathrm{x}$ ray PA view proved normal. CT scan showed growth in posterior one third tongue. Her pre treatment serum LDH was 402.24 IU/litre. Post radiotherapy serum LDH came as $198.11 \mathrm{IU} /$ litre. All other nine cases were males. Among which five were well differentiated squamous cell carcinoma of oropharynx. Four belong to moderately differentiated squamous cell carcinoma category. Only one patient belongs to T4 staging. Among the cancer patients of oropharynx, seven were chronic smokers and alcoholics, two were chronic smokers alone. Female had tobacco chewing history. 


\section{Supraglottis:-}

20 patients were proven carcinoma supraglottis. Among 20 patients, only one was female, aged 28 years proven neuro endocrine tumour of larynx moderately differentiated belong to T3 stage III category. She underwent total laryngectomy with thyroidectomy. Her pretreatment level was 347.24 and postsurgical value dropped to 248 . Remaining 19 patients were males, among which 1 patient underwent surgery, whose pretreatment values was 380 and post treatment value 288.65. Among the 19 patients other than females, 5 were well differentiated head and neck squamous cell carcinoma. 10 patients belonged to moderately differentiated squamous cell carcinoma. 4 patients were of poorly differentiated squamous cell carcinoma. Among well differentiated group, 1 patient belongs to T1, 2 were T2, 2 were T3. Only one patient was a chronic smoker and alcoholic. Among the 10 moderately differentiated group, 5 patients were T2, 4 patients T3, 1 patient T4.

4 patients were of poorly differentiated group. 1 patient T3, 3 patients T4.

From supraglottic tumour, pre treatment and post treatment values we arrived at a conclusion that pre treatment serum LDH was higher and dropped to lower values after treatment whatever may be the modality of management, surgery or radiotherapy. One another factor which has been arrived at is T4 stage showed increased pre treatment serum LDH value than T1 stage. Similarly pre treatment serum LDH value showed a progressive increase and when we move through T1 to T4. That shows serum LDH increases with increase in tumour staging. Also seen poorly differentiated tumours showed high serum LDH values than moderate and well differentiated tumours. Except female patients in carcinoma supra glottis, all others were chronic smokers and alcoholics. Only duration and quantity of exposure varies.

\section{Glottis:-}

Out of 11 cases of proven carcinoma glottis, 1 patient 50 years male, who is a proven moderately differentiated carcinoma T3 stage whose pre treatment value was 302 IU/litre and post surgical value was 186 IU/litre. He underwent total laryngectomy with partial thyroidectomy. Among the remaining 10 cases, 5 were well differentiated, 4 were moderately differentiated, 1 poorly differentiated. Among 11 cases 6 were T3, 3 were T2, 1 belongs to T1. Among the 11 patients only 6 were chronic smokers and alcoholics, remaining 5 were occasional smokers and social alcoholics.

\section{Carcinoma Subglottis:-}

Only one female among the 50 patients proved to be squamous cell carcinoma sub glottis. Staging T2N0M0 moderately differentiated squamous cell carcinoma. Her pre treatment serum LDH showed 359.11IU/litre and post treatment was 220.16. She was not a tobacco chewer or an alcoholic.

\section{Carcinoma Hypopharynx:-}

9 cases of carcinoma hypopharynx was studied. Only 1 was female patient with moderately differentiated squamous cell carcinoma. Tumour staging was T2. Her pre treatment LDH showed 386.26IU/litre and post treatment 160.18 IU/litre. Only one patient belongs to T4Bstage, 3 patients were of T3 stage, 4 patients belonged to T2 stage. This shows tumours of hypopharynx present for treatment at a relatively advanced stage. Presentation at T1stage was rare. Patient usually comes for treatment when symptoms of dysphagia progresses. Commonest presentation of CA hypopharynx is T2 stage with no node. Pyriform sinus tumour present with cervical lymphadenopathy than with any other subsite.

Head and neck tumours are common in INDIAN sub continent. In the above study, percentage of carcinoma supra glottis is common followed by carcinoma oropharynx, carcinoma glottis, hypopharynx and last sub glottis. Average age of malignant tumors in male is 60 years and female it is 47 years. The reason for which male being more commonly affected than female is increased habit of smoking, alcohol with tobacco chewing in males compared with females. Symptoms with which head and neck malignant tumour patients presented to OPD includes dysphagia, change in voice, difficulty in breathing, hoarseness of voice, cervical lymphadenopathy.

Out of the 50 patients in this study, totally 3 patients underwent surgery, remaining 47 underwent radiotherapy. There is no difference in serum LDH reduction level in both surgery and radiotherapy patients. Similarly for well, moderately or poorly differentiated tumours also the reduction in serum LDH level showed no correlation with the differentiation or stage of tumour. 
Malignancies of head and neck constitute 50-70\% of cancers diagnosed in INDIA. The overall survival rate for some subsites is less. The poor survival is contributed to late presentation, poor accessibility ,lack of awareness. The key factor in increasing survival is early detection and treatment of the disease and recurrence. This study attempts to enlighten a parameter that would facilitate the above idea.

In the present study of head and neck squamous cell carcinoma ,the mean serum LDH level in control group was $236 \mathrm{IU} / \mathrm{L}$ for males and $198 \mathrm{IU} / \mathrm{L}$ for females. This is within the normal lab control of $120-246 \mathrm{IU} / \mathrm{L}$. in the study group the pre treatment level of serum LDH was $331.92 \mathrm{IU} / \mathrm{L}$ for radiotherapy group and 343 IU/L for surgery group . These values are grossly above the normal level. The post treatment values of serum LDH for radiotherapy and surgery group are 206.42 IU/L and 240.66 IU/L respectively. These values are within the normal lab control values.

This proves the fact that serum LDH is elevated in patients with head and neck malignancy .The study shows serum LDH levels decrease to normal level following curative therapy irrespective of the modality of therapy.

From this study we also see the pre treatment LDH levels vary with the degree of differentiation of tumor. the well differentiated tumors have mean serum LDH levels of 312.88 IU/L, moderately differentiated 327.07 IU/L, poorly differentiated tumors $393.14 \mathrm{IU} / \mathrm{L}$. this shows the levels increase with increasing grades of tumor.

Another factor derived from the study is serum LDH levels also correlate with size of the tumor .t2 stage exhibit a mean of 367.53 IU/L compared to $\mathrm{t} 1$ stage which showed mean of $286 \mathrm{IU} / \mathrm{L}$ pre treatment. Similarly t4 stage showed pre treatment mean of $363.66 \mathrm{IU} / \mathrm{L}$ compared to $312.37 \mathrm{IU} / \mathrm{L}$ in $\mathrm{t} 3$. Serum LDH seems to correlate with size of the tumor as larger tumor have more cells from which enzymes might leak into blood or larger necrotic fraction so that the enzymes leak into blood as a result of cell break down.

One other interesting factor to emerge from the study is serum LDH levels also correlate with dissemination of disease. The levels are higher in patients having metastasis to cervical node than those with No neck. In this study 29 patients had cervical node metastasis clinically and none of the patients had systemic metastasis which is also uncommon in head and neck cancers.remaining 21 patients had no clinical and radiologically detectable metastasis. The serum LDH levels for metastatic group was 342.19IU/L and for non metastatic group was 321.55IU/L . Other serum enzymes like serum adenosine deaminase and phosphate hexose isomerase does not show this correlation.

\section{Conclusion:-}

From this study, the following conclusions are arrived

1. Serum LDH is consistently elevated in head and neck squamous cell carcinomas.

2. The rise in serum level is irrespective of the site of origin of tumor.

3. The enzyme increase in other histological types is not evaluated in this study

4. The rise in enzyme level increases with the size of the tumor and shows higher levels in larger tumors compared with smaller ones.

5. The serum LDH levels also correlate with the histological grade of malignancy . Poorly diifferentiated carcinoma shows largest level followed by moderately differentiated and then well differentiated tumors.

6. The levels are significantly higher in patients with metastasis than those without metastasis.

7. From this study it is concluded that serum LDH levels decrease to within normal range in patients treated by curative therapy. All patients show significant fall in levels following radiotherapy or surgery.

8. The fall in level is irrespective of the curative treatment modality.

9. Morphological type of tumor does not show any correlation with enzyme levels

10. As the enzyme level falls with therapy, this could be used for follow up of the patient to detect recurrences.

11. This test can be used to screen high risk patients at primary care level since the procedure is easy and cost effective.

It is said cancer is very easy to see than to foresee. By periodically screening persons with risk factors with simple procedures malignant changes can be detected at incipient stage. When a malignancy is still cytological than histological cure can be given. Smoking and alcohol were found to be the main etiological factors. Health education and periodic screening will help early detection of head and neck malignancy and will go a long way in men's quest to weed out diseases and improve the quality of life . 


\section{Bibliography:-}

1. Willis ra : the spread of tumors in human body.london.

2. Singh b. Molecular pathogenesis of head and neck cancer.journal of surgical oncology 2008 ; 97:634-9

3. Gasco m,crook t.the p53 network in head and neck cancer.oral oncology 2003;39:222-31

4. Ho t, wei,sturgis em. Epidemiology of carcinogen metabolism genes and risk of squamous cell carcinoma of the head and neck.head and neck 2007;29:682-99

5. du w,searle js.the rb pathway and cancer therapeutics.current drug targets 2009;10:581-9.

6. Foulkes wd,brunet js,sieh w et al .familial risks of squamous cell carcinoma of the head and neck:retrospective case-control study.british medical journal 1996;313:716-21.

7. Kalyankrishna s, grandis jr.epidermal growth factor receptor biology in head and neck cancer.journal of clinical oncology 2006;24:2666-72.

8. Storey a,thomas $\mathrm{m}$, kalita a et al role of a p53 polymorphism in the development of human papilloma virus associated cancer.nature 1998;393:229-34.

9. Mork j, moller b,glattre e. Familial risk in head abnd neck squamous cell carcinoma diagnosed before the age of 45:a population based study.oral oncology 1999;35:360-7.

10. Quon h,liu ff,cummings bj.potential molecular prognostic markers in head and neck squamous cell carcinomas.head and neck 2001;23:147-59.

11. bahno.national minimum and advisory head and neck cancer data sets.british association of head and neck oncologists, 1999.

12. 12. Thawley s.e.and o'leary m.o $\{1992\}$ malignant neoplasms of the oropharynx, in otolaryngology-head and neck surgery (c.w,cummings,j.fredrickson, 1.a harker,c.j krause and d.e.schuller,eds),mobsy,st louis,mo,chap.74,p.1313.

13. Shah j.p(1996) oral cavity and oropharynx,in head and neck surgery,2 nd edn,mosbywolfe,london,chap.6,pp167-234

14. Jakobsson p.a.,eneroth c.m.,killiander d.,moberger g.and martensson b.(1973) historical classification and grading of malignancy in carcinoma of the larynx,acta radiol ther phys biol 12;1-8

15. stell and maran head and neck surgery,4 th edition

16. elias m.m.,hilgers f.j.,keus r.b., gregor r;t.,hart a.and balm a.j.(1995) carcinoma of the pyriform sinus; a retrospective analysis of treatment results over a 20year period,clin otolaryngol appl sci20:249-53

17. hoe c.n.,lamb k.h.,ng w.f and wei w.i.(1996) pathological basis for hypopharyngeal cancer,in proceedings of the ivth international conference on head and neck cancer,the society of head and neck surgeons,alrington,va and the american society of head and neck surgery,pittsburgh,pa,pp.149-55

18. yu mc,huang tb,henderson be :diet and nasopharyngeal carcinoma: a case- control study in guangzhou,china.int j cancer 43:1077-1082,1989.

19. pinkerton ke, et al: interaction of tobacco smoking, with occupational and environmental factors. In harber ph,et al (eds):occupational and environmental respiratory disease.st.louis,mosby ,1996,pp827-835.

20. mak-kregar s ,hilgers fjm,levendag pc ,manni jj, lubsen $\mathrm{h}$, roodenburg jl et al.a nationwide study of the epidiomology,treatment and survival of oropharyngeal carcinoma in the netherlands.european archieves of oto rhino-laryngology.1995;252:133-8. 